\title{
Relações Históricas entre Itália e Tunísia e o Caso Khlaifia e Outros vs. Itália da Corte Europeia de Direitos Humanos
}

\author{
Historical Relations between Italy and Tunisia and the Case \\ Khlaifia and Others vs. Italy from the European Court of Human \\ Rights
}

\section{Estela Cristina Vieira de Siqueira ${ }^{1}$}

\begin{abstract}
Resumo: O caso Khlaifia e outros vs. Itália, sobre a detenção de migrantes em centros inadequados de acolhida na Ilha de Lampedusa e em Palermo, confronta diretamente a fragilidade da proteção dos direitos fundamentais das pessoas que migram no contexto atual da União Europeia, sendo tratados como um elemento passível de securitização, ao invés de receptores e destinatários de bem engendradas políticas de acolhimento, sobretudo àqueles em contextos de migração forçada. Optou-se pelo método analíticodedutivo de pesquisa, a partir de revisão bibliográfica, com a análise de informações constantes do banco de dados da União Europeia e da Corte Europeia de Direitos Humanos, sobre o caso específico e outros que embasassem os argumentos ora apresentados, dentro de uma sistematização de duas fases de pesquisa: uma análise contextual e histórica das relações entre Itália e Tunísia e, em um segundo momento, o caso Khlaifia, propriamente dito. Nesse sentido, o passado histórico da Europa colonizadora dos séculos anteriores e, sobretudo, da Itália, sempre a estabelecer laços próximos com a Tunísia, revela um paradoxo sobre a livre circulação, dentro dos restritivos limites da categorização e hierarquização dos vistos de ingresso na nova Europa, de portas abertas aos cidadãos europeus, mas não extensível a países outrora colonizados e/ou antigas zonas de interesse econômico.
\end{abstract}

Palavras-chave: Itália. Tunísia. Detenção. Migração. Colonização.

\begin{abstract}
The case Khalifia and Others v. Italy, on the detention of migrants in inadequate accommodation centers on the Island of Lampedusa and Palermo, directly confronts the fragility of the protection of the fundamental rights of migrants in the current context of the European Union and they remain treated as securitizable elements, rather than recipients of well-engineered welcoming policies, especially to those in contexts of forced migration. The methodological option went for the analytical-deductive method of research, based on a bibliographic review,
\end{abstract}

\footnotetext{
1 Doutoranda em Direito Internacional pela Faculdade de Direito da Universidade de São Paulo (USP). Mestre pela Faculdade de Direito de Sul de Minas (2017). Bacharel em Direito pela Faculdade de Direito de Varginha (2014). Membro da Comissão Estadual de Direitos Humanos da OAB/MG. Atualmente é professora de Teoria Geral do Estado e Direito Internacional da Faculdade Três Pontas (FATEPS), integrada ao Centro Universitário do Sul de Minas (UNIS), e professora de Direito Internacional e Direitos Humanos da Escola Mineira de Direito (EMD). Advogada. ORCID n. 0000-0003-4188-8264.
} 


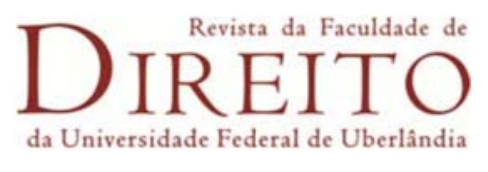

with the analysis of information contained in the database of the European Union and the European Court of Human Rights, about the specific case and others that support the arguments presented herein. Thus, the present work was developed within a systematization of two research phases: a contextual and historical analysis of the relations between Italy and Tunisia and, in a second moment, the Khlaifia case itself. In this sense, the historical past of Europe as colonizers, in the previous centuries and, specifically, of Italy and the Roman Empire, always establishing close ties with Tunisia, reveals a paradox about free movement, within the restrictive limits of the categorization and hierarchy of entry visas in the new Europe, opened to European citizens, but not encompassing of formerly colonized countries and/or former zones of economic interest.

Keywords: Italy. Tunisia. Detention. Migration. Colonization.

\section{Introdução}

Caso paradigmático sobre a detenção de migrantes em contextos de deslocamento forçado, Khlaifia e outros vs. Itália, da Corte Europeia de Direitos Humanos, representa um marco quanto à afirmação de direitos individuais das pessoas que migram, sobretudo em um contexto geográfico e histórico tão entrelaçado como se observa entre a Itália e a Tunísia - um paradoxo entre a importância estratégica dos portos africanos e os obstáculos ao acolhimento de estrangeiros na Europa, além de inflamar inúmeros debates sobre xenofobia e preconceito, evidenciando um comportamento institucional preocupante e comum a vários países europeus.

A decisão sobre a condição degradante dos centros de detenção na Itália, bem como inúmeras outras violações cometidas em uma conjuntura de grandes fluxos de pessoas, em decorrência dos eventos da denominada Primavera Árabe, na qual diversos levantes a governos da região do Magreb, o noroeste da África, ocorreram, sem que a Corte, no entanto, desconsiderasse também as dificuldades enfrentadas pelos países europeus com relação ao fenômeno dos movimentos humanos e sua infraestrutura para acontecimentos desse porte.

A Guarda Costeira da Itália realizou a detenção, em setembro de 2011 (GOLDENZIEL, 2018), do Sr. Saber Bem Mohamed Ben Ali Khlaifia e outros 
migrantes tunisianos, e procedeu com o trânsito destes até o Centro di Soccorso e Prima Accoglienza (CSPA) da Ilha de Lampedusa, localizada a apenas $167 \mathrm{~km}$ de Ras Kabudia, na Tunisia.

No entanto, apesar de o momento ser de resistência por parte da República Italiana em acolher imigrantes - sob a argumentação de falta de infraestrutura -, historicamente, a Itália sempre manteve boas relações com a Tunísia, em razão de sua posição geográfica, desde o Império Romano, tendo sempre sido alvo do colonialismo italiano, muito embora tenha se tornado, em 1881, colônia da França. Agora, contudo, esse histórico se converte em hostilidade no próprio território.

Tais fatos também contrastam com o fato de que a retórica da mesma Europa difusora de direitos fundamentais de matriz essencialmente europeia, impostos muitas vezes de forma agressiva às outras regiões do globo, agora, nas palavras de Marie Laure Basilien-Gainche (2017), prefere ver migrantes mortos no mar a acolhê-los em próprio solo.

Dessa maneira, considerando-se o contexto histórico e a relevância da decisão da Corte Europeia de Direitos Humanos para o fortalecimento dos direitos dos migrantes no continente europeu, partindo do pressuposto de que a Europa possui, também, desde o advento da União Europeia, uma configuração política de fronteiras (Espaço Schengen), contrastando com o conceito mais tradicional de fronteira geográfica, limitante dos contornos do Estado - podemos falar em um paradoxo da livre circulação, restrita aos cidadãos provenientes de países da Zona Schengen, mas não extensível a países outrora colonizados e/ou antigas zonas de interesse econômico?

Sob o ponto de vista metodológico, a fim de proceder com a melhor abordagem do tema, foi feita opção pelo método analítico-dedutivo de pesquisa, partindo da pesquisa bibliográfica como técnica de pesquisa, com a análise de informações constantes do banco de dados da União Europeia e da Corte Europeia de Direitos Humanos. 


\section{Breve Contextualização das Relações Históricas entre Itália e Tunísia}

Muito embora tanto se fale sobre as migrações através das águas azuis do Mediterrâneo no século XXI, é fato que, historicamente, a região sempre foi uma das principais rotas migratórias do mundo e das relações políticas e econômicas estabelecidas em suas águas deriva a prosperidade e o declínio das principais civilizações limítrofes.

A Itália, não obstante possa nos remeter também à trajetória do Império Romano e seu caráter eminentemente expansionista, possui um histórico bastante recente de unificação de Estado (CHOATE, 2010), como a nova Itália, cuja política econômica e de emigração se relaciona, mais uma vez, com um momento de expansão imperialista que envolve, entre outros territórios, a Tunísia.

A Itália de Vitório Emanuelle II precisava se afirmar - centros econômicos como Trani, Amalfi, Sicília, Pisa, Gênova e Veneza (MANCINI, 2003), colocaram o novo Estado no centro do mundo mercantil, o que levou a criação de leis marítimas e comerciais específicas (CHOATE, 2010) dentro de uma necessidade de projeção colonizadora, em uma nova realidade de poder que dependia da aquisição e capacidade de influenciar novos territórios.

Diferentemente de outros contextos de emigração, o Estado italiano continuou se identificando fortemente com os italianos em comunidades extramarinas, seja no próprio Mediterrâneo, na Europa, como um todo, ou nas Américas. No entanto, a influência da Itália exercida sobre outras nações é frequentemente ignorada em estudos sobre colonialismo, e a localização estratégica e geográfica do Mediterrâneo guiou muito do interesse italiano.

A Tunísia, um importante porto, a pouco mais de 145 quilômetros da Itália (CHOATE, 2010), através do Estreito da Sicília, era uma posse importante para a Itália, que desenvolveu elaborados laços culturais, sociais 
e econômicos com a Tunísia, antes que a França a tomasse como colônia, em 1881, frustrando as aspirações coloniais italianas. Lampedusa e as demais

Ilhas Pelagias, como se pode denotar do mapa abaixo, ficam mais próximas do país africano do que da própria Europa.

\section{Mapa 1 - Estreito da Sicília}

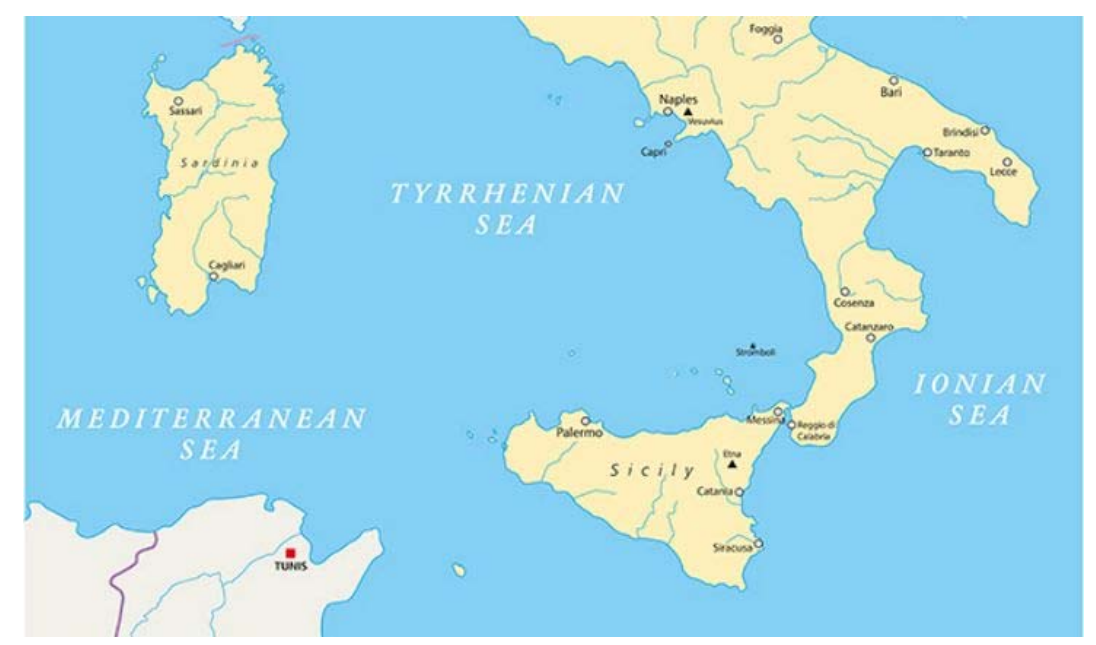

Extraído de: WORLD ATLAS, 2019 - mapa por Oishimaya Sem Nag.

Como colônia francesa, havia muito mais italianos na Tunísia do que franceses, e a França tomou a Tunísia como colônia de exploração (CHOATE, 2010), com objetivos meramente extrativistas, ao invés de fazê-lo como colônia de assentamento, como aconteceu com a vizinha Argélia.

A Itália, tentando combinar as formas de colonialismo formal, da Roma antiga, e informal, de Veneza e Gênova, perdeu a oportunidade de tomar para si a Tunísia, entre as duas definições. Sem desempossar os berberes e os árabes, que cultivavam a agricultura, milhares de italianos se deslocaram para as cidades tunisianas na década de 1870 (CHOATE, 2010), em razão do país africano representar uma interessante zona econômica.

Isso também se relaciona com outras questões históricas internas da própria Itália e sua recente unificação enquanto Estado, pois nem todas as suas regiões se desenvolveram de forma igualitária, evidenciando uma divisão entre Norte e Centro desenvolvidos, e um Sul referido frequentemente 
como sendo a "beirada" (GIGLIOLI, 2017) da Europa, rural, e habitualmente culpada pela classe política por todas as dificuldades econômicas da Itália, apesar de sua localização estratégica - dificuldades que levaram muitos italianos a emigrar a outras regiões, como as Américas, o Norte Europeu e a própria África.

No entanto, a Tunísia segue central a duas visões distintas: sua posição geográfica privilegiada no Mediterrâneo, o que a tornaria interessante à colonização - sobretudo de uma Itália recém unificada, e carente de autoafirmação -, e sendo um país africano, mas com forte identificação europeia, principalmente dos italianos que migraram para o país e que não compartilhavam da mesma identificação abstrata e um tanto fabricada da Itália unificada, identificando-se muito mais com o local onde viviam, do que com o país Europeu de origem.

Ainda, enquanto colônia francesa, assim como a Líbia e a Albânia, também fez parte do Império Romano, mas a comunidade italiana à época da colonização pela França se assemelhava mais às comunidades italianas de São Paulo e Buenos Aires (CHOATE, 2010), ligada à pretensa metrópole italiana mais por laços culturais e econômicos do que por quaisquer tipos de traços de dominação. Inclusive, sob o aspecto de identificação, os próprios franceses não viam distintamente os sicilianos da classe trabalhadora da Tunísia e os tunisianos nativos, sujeitos dos processos colonizatórios, per se (GIGLIOLI, 2017). Inclusive, a forma de organização tanto de tunisianos e sicilianos, no que diz respeito ao trabalho agrícola na Tunísia, era muito própria dos povos árabes, e deveras semelhantes, em ambos os casos (LOTH, 1905).

Isso ocorria desde o século XII, com os venezianos, seguidos pelos judeus e os cristãos de Livorno e de parte da Toscana, pescadores da Sicília, seguindo os passos da Roma antiga na tomada de Cartago (CHOATE, 2010). Assim, fica evidente que a mesma Europa colonizadora que exportou milhões 


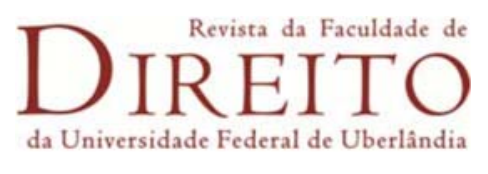

de europeus às mais diversas regiões do globo nos séculos anteriores, lida, agora, com os migrantes sob rígido controle de fronteira, no terceiro milênio.

\section{Caso Khlaifia e Outros vs. Itália e as novas fronteiras Europeias} Breve Contextualização das Relações Históricas entre Itália e Tunísia

As migrações fazem parte da realidade cotidiana da Europa desde tempos imemoriais e sua composição étnica, sobretudo dos países limítrofes a outros continentes, é diversa, não apenas em território próprio, mas também em territórios outros, em razão de extensivos períodos de colonização, aos quais as grandes potências europeias submeteram extensas porções territoriais por todo o globo, no denominado "Novo Mundo" - cujas menções colonialistas perduram até hoje, inclusive em instrumentos internacionais, como é o caso do artigo 38 do Estatuto da Corte Internacional de Justiça, com seus "princípios gerais de direito reconhecidos pelas nações civilizadas" (CÂMARA DOS DEPUTADOS, 1945).

No entanto, o caráter eminentemente humanitário que gradualmente se confere em maior proporção aos atuais fluxos migratórios expõe uma outra característica das políticas europeias, sobretudo quanto à concessão e distribuição dos tipos de vistos de ingresso na União Europeia aos migrantes desejáveis e indesejáveis. O que se vê é a construção de uma fronteira adicional, política, com a construção de muros, de sistemas de segurança reforçados e sensores térmicos de movimento que ultrapassam os limites tradicionais de território e fronteira, interferindo nos limites de países vizinhos (BERKES, 2018) - sobretudo em fronteiras continentais interiores, como ocorre com países como a Hungria.

Nesse sentido, no que diz respeito à jurisdição dos Estados quanto ao controle de fronteira, a União Europeia instituiu a Frontex, a agência 


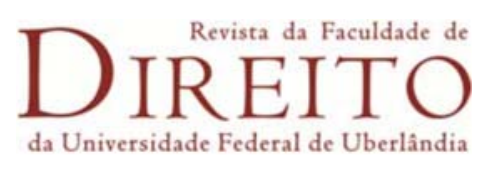

responsável pela implementação do controle de migração, a mesma que se vê realizando manobras de interceptação de botes e embarcações com migrantes nas águas do Mediterrâneo, nas denominadas "push back operations", amplamente criticadas - uma utilização da tecnologia e do cadastro biométrico de seres humanos em desfavor à proteção de seus direitos fundamentais (HAYES; VERMEULEN, 2012).

Essas operações, no entanto, carecem de substância jurídica para sua realização, tendo esse tipo de interceptação marítima sido previamente julgado pela Corte, no caso Hirsi Jamaa vs. Itália, sobre a devolução de migrantes da Somália e da Eritréia a seus portos de origem, na primeira leva de migrantes da Líbia que chegariam à Itália, em 2009, sem que a eles fosse concedida a possibilidade de se valerem dos remédios eficazes à sua proteção e/ou à solicitação de asilo, e sem que Itália e Líbia se responsabilizassem pela proteção dos migrantes, em clara violação do princípio do non-refoulement (GIUFFRÉ, 2012).

Ainda, antes de adentrar especificamente nos pormenores do caso Khlaifia e Outros vs. Itália, a base legal inexistente para as push back operations da Frontex nos confronta com a responsabilidade dos Estados para com a proteção dos direitos humanos das vítimas, consideradas como tal em ambos os casos, e sobre se a responsabilidade primária por eventuais riscos e danos irreparáveis poderia ser pronunciada contra membros da União Europeia, em situações análogas (GIUFFRÉ, 2012).

Tal preocupação com a responsabilidade de Estado se traduziria, posteriormente, em 2017, na Convenção de Dublin, de forma a agilizar os procedimentos de concessão do status de refúgio para os indivíduos que se encontrem incluídos na definição prevista na Convenção de 1951, sendo o primeiro país de ingresso o encarregado pelo processamento das solicitações, obrigatoriamente (EUROPEAN UNION PUBLICATIONS OFFICE, 2017).

Nesse sentido, sobre o princípio do non-refoulement e a proteção internacional que acompanha aqueles que migram involuntariamente, por 
força de fundado termor de perseguição, que coloque sua vida em risco (BERKES, 2018), conforme a definição apresentada na Convenção sobre o Estatuto dos Refugiados, de 1951, fica disposto em seu artigo 33 (1) que

\begin{abstract}
Aucun des Etats contractants n'expulsera ou ne refoulera, de quelque manière que ce soit, un réfugié sur les frontières des territoires où sa vie ou sa liberté serait menacée en raison de sa race, de sa religion, de sa nationalité, de son appartenance à un certain groupe social ou de ses opinions politiques. (ORGANIZAÇÃO DAS NAÇÕES UNIDAS, 1951).
\end{abstract}

Enquanto milhares de vítimas de conflitos armados e situações análogas arriscam as próprias vidas em trajetórias, a Europa lida com os migrantes da Primavera Árabe sob um aspecto meramente securitário, invertendo a retórica política da metade do século XX, que daria origem aos principais mecanismos de direitos humanos, de matriz profundamente europeizada e cristã - "l'Union et ses États cherchent à se proteger de ceux qui on besoin d'être par eux protégés” (BASILIEN-GAINCHE, 2017).

Dessa maneira, o que se vê por toda a Europa é uma política de encampamento de migrantes (BASILIEN-GAINCHE, 2017), em condições análogas às de detenção, como se poderá verificar da análise do caso base do presente estudo. De forma consonante, a Corte Europeia de Direitos Humanos emitiu uma opinião com implicações altamente relevantes sobre a forma com a qual os Estados devem se relacionar com os direitos individuais das pessoas que migram, versando especificamente sobre a detenção de migrantes no Centro di Soccorso e Prima Accoglienza (CSPA, na sigla em italiano) da Ilha de Lampedusa, mas com interpretações extensíveis a outras ocorrências.

O principal fato narrado no caso versa sobre o status migratório do Sr. Saber Ben Mohamed Ben Ali Khlaifia e de outros indivíduos em situação igual ou semelhante, todos provenientes da Tunísia e em deslocamento forçado, devido aos eventos ocorridos durante o fenômeno político denominado Primavera Árabe, tendo estes migrantes sido conduzidos pela Guarda Costeira da Itália à Ilha de Lampedusa, em setembro de 2011 (EUROPEAN COURT OF HUMAN RIGHTS, 2015). 
Sob o aspecto da qualidade de suas instalações, os CSPAs são considerados relativamente melhores que outras estruturas pelos migrantes, em razão do tratamento menos precário e degradante que a eles é dispensado nos centros de Identificação e Expulsão de Estrangeiros (Centro di Identificazione ed Espulsione - CIE), em razão da diferença na administração dos dois estabelecimentos: os CSPAs têm suas operações conduzidas pela União Europeia, e sob suas regras são regulamentados, enquando os CIEs permanecem sob a égide da administração e da legislação da Itália.

Nas alegações apresentadas pela República Italiana, teria havido individualização no preenchimento das informações em cada formulário migratório, para cada um dos migrantes, fato amplamente contestado, pois não há comprovação documental de tal afirmação.

O que se sabe, no entanto, é que os migrantes foram mantidos pelo período de três dias em condições degradantes, sem condições mínimas de higiene, por um período de 3 dias, no qual foram forçados a dormir no chão e a realizar suas refeições diárias no chão. Ainda, de acordo com as alegações dos migrantes no caso, o centro fora mantido durante todo o período com um forte esquema de segurança, sem que fosse possível qualquer contato por parte dos solicitantes com o mundo exterior, o que caracterizaria a alegação de detenção.

Nesse sentido, reportando-se ao contexto europeu no qual as migrações ocorreram, Basilien-Gainche menciona a fragilidade do poder e a relatividade dos direitos fundamentais e sua aplicação, em uma Europa que age permanentemente como se estivesse "sitiada", pois uma Europa com 511 milhões de migrantes em meados da segunda década do século XXI não é necessariamente incapaz de acolher a atual população de 2 milhões de migrantes (BASILIEN-GAINCHE, 2017).

O que se percebe, portanto, é que o migrante passa a ser a encarnação da própria fronteira, a materialização das restrições de ingresso, fazendo com que a comunidade europeia, liberal em geral, renuncie a certos princípios 
essenciais, em prol dessa securitização exacerbada, encubadora de uma categorização de humanos, sob o pretexto de a eles conceder vistos distintos de ingresso, de acordo com seus perfis étnicos e econômicos (BASILIENGAINCHE, 2017) - paradoxal, para um espaço que não é, de fato, liberal para todos, e um contraste com a conjuntura histórica colonizadora e imperialista do passado europeu - e mesmo do jus communicationis de Vitória e a descoberta de novos territórios através da pretensa (e falaciosa) aproximação dos povos, salvo quando o contrário se fizesse necessário, o que denotava o caráter feroz e pouco amistoso da colonização europeia (LICARI, 2011).

Conforme já mencionado sobre a situação histórica entre Itália e a Tunísia, agora, o fluxo não é mais entre metrópole e a colônia pretendida, mas inverso - a rota mais mortal de migração da atualidade leva milhares de migrantes do norte da África e do Oriente Médio ao azul cristalino do Mediterrâneo e não com a mesma naturalidade por parte da Europa, quando ocorrida em sentido inverso, evidentemente.

Sob o aspecto jurídico, quanto ao atual tratamento dispensado aos migrantes, há que se considerar o Tratado de Amsterdã, de 1997, que declara que a União Europeia se funda nos princípios da liberdade, da democracia, do respeito aos direitos fundamentais e às liberdades individuais, e na Carta Europeia de Direitos Fundamentais. Embora haja a problemática modificação da expressão "princípios" para "valores", a Europa segue, juridicamente, adotando a dignidade da pessoa humana como fundamento, o que é reforçado pelo Tratado de Lisboa, de 2007, o que tem sido por vezes esquecido na maneira com a qual a Europa lida com os migrantes, como uma ameaça, a depender de seu lugar de origem.

E partindo também do pressuposto de que a Europa possui desde o advento da União Europeia, uma configuração política de fronteiras (Espaço Schengen) (BASILIEN-GAINCHE, 2017), contrastando com o conceito mais tradicional de fronteira geográfica, limitante dos contornos do Estado, o que se opera é, de fato, um paradoxo da livre circulação, que não é para todos, e 
enfatiza ainda mais o caráter discriminatório da categorização de migrantes constante dos artigos 78 e 79, criando uma hierarquia de status.

Detidos estritamente por sua condição migratória e submetidos a condições degradantes, houve uma revolta de migrantes no CSPA da Ilha de Lampedusa, na qual houve destruição de parte da estrutura, em um incêndio provocado pelos revoltosos, tendo sido conduzidos a outras instalações, dessa vez na capital da Sicília, Palermo. No local, foram alojados nos navios Vincent e Audace, confinados nas áreas de alimentação das embarcações, impedidos de acessar as cabines, dormindo, portanto, no chão, e tendo de aguardar horas para utilizar os sanitários, tendo autorização de saída aos decks apenas 2 vezes por dia, por poucos minutos (EUROPEAN COURT OF HUMAN RIGHTS, 2015), insultados e maltratados pela polícia, que os mantinha em forte esquema de vigilância e segurança, ainda sem qualquer tipo de contato com o mundo externo.

Nessas condições, os solicitantes foram mantidos nas embarcações por quase uma semana, até dois deles foram conduzidos até o aeroporto de Palermo, em 27 de setembro. O Sr. Khlaifia, que dá nome ao caso, chegaria ao aeroporto apenas no dia 29. Antes de serem deportados, eles se encontraram com o Cônsul da Tunísia, que realizaria um registro de suas identidades, sob a alegação de tal procedimento estar em conformidade com um acordo entre Itália e Tunísia, de abril de 2011. O texto desse acordo, no entanto, jamais se tornou público, não sendo possível realizar afirmações sobre seu texto ou existência, tendo sigo apresentadas, conforme os parágrafos 36 a 40 do caso, apenas as minutas das negociações. Ademais, uma note verbale mencionada pela Itália não possui aplicação ao mencionado no caso (EUROPEAN COURT OF HUMAN RIGHTS, 2015).

A Itália afirmou também em suas alegações ter emitido três refusalsof-entry, todas no idioma nativo dos solicitantes, o árabe, nas quais foram elaboradas as razões próprias para a recusa de cada um dos tunisianos. Eles, no entanto, dizem nunca ter recebido qualquer tipo de documento durante sua 
estadia na Itália, conforme o parágrafo 19 da decisão (EUROPEAN COURT OF HUMAN RIGHTS, 2015).

Grupos de direitos humanos e associações contra o racismo se tornaram simpatizantes à causa e realizaram denúncias criminais contra os oficiais de Palermo, sobre a maneira como os migrantes haviam sido tratados nos navios Audace e Vivace e ainda um terceiro navio, o Fantasy, sem que nenhuma lograsse êxito, sob a alegação do Juízo de Paz de Agrigento, na Sicília, de que não havia fundamentação suficiente para que medidas penais fossem tomadas contra os oficiais responsáveis.

Porém, ainda no Juízo de Paz de Agrigento, também na Sicília, dois migrantes conseguiram a anulação das ordens, em 4 de julho e 30 de outubro de 2011, respectivamente. Em 6 de março de 2012, a Comissão Especial de Direitos Humanos do Senado Italiano aprovou um relatório sobre as condições do CSPA de Lampedusa, seguindo-se a uma visita da comissão, em 11 de fevereiro de 2012.

Os solicitantes, então, levaram o caso à Corte Europeia de Direitos Humanos, alegando a violação dos artigos 3, 5 e 13 da Convenção Europeia de Direitos Humanos, sendo o artigo 4 do Protocolo 4 à Convenção e o artigo 3 da Convenção alegados sozinhos ou em conjunto ao artigo 13, também do texto principal, sobre os seguintes temas, respectivamente: o artigo 3 versa sobre a proibição de tratamento cruel, desumano ou degradante, o artigo 5 trata sobre a obrigatoriedade do devido processo legal em situações de detenção, o artigo 13 versa sobre a garantia de remédios eficazes a todos os direitos postos na Convenção e o artigo 4 do Protocolo 4 menciona a proibição de expulsão coletiva, sendo alegado sozinho ou em conjunto com o artigo 13.

A Itália, segundo alegaram os solicitantes, os havia privado de liberdade sem que fossem expostos os motivos para a detenção e sem a possibilidade de acessarem o devido processo, de forma a contestar sua privação de liberdade. Sobre esse aspecto, especificamente, a Itália não contestou o fato de que, realmente, a polícia exercia o procedimento de 
segurança e controle desses centros, ou mesmo sobre o impedimento dos migrantes deixarem o local do CSPA, porém, alegou que tais medidas, como a de permanência dos solicitantes em um centro inadequado, foram, de acordo com os parágrafos 59 e 60, medidas administrativas de logística emergencial e humanitária, sendo, portanto, um caso de "acomodação" e não de "confinamento", o que fora contestado pelo Centro de Direitos Humanos e Pluralismo Jurídico da McGrill University, no parágrafo 63, mencionando o caso Abdolkhani and Karimnia v. Turkey, no qual a Corte desconsiderou o argumento do governo turco sobre "acomodação" em centros inadequados.

A Corte, nesse sentido, alega que a argumentação sobre privação de liberdade é bastante tênue, variando em grau e intensidade, e que casos limítrofes, como tal se observava, poderiam estar sujeitos à "pura opinião", compreendendo diferentemente do alegado pelo McGrill Centre, no sentido de que, de fato, a Itália, em razão da emergência dos eventos, não estava em condições de prover centros adequados, tendo, no entanto, concordado com a violação ao artigo 5, pois os migrantes não poderiam ter sido mantidos detidos de forma arbitrária, sem clara fundamentação na legislação doméstica, tendo sido, de fato, privação de liberdade, pois além da restrição de movimento, a segurança constante caracterizava a detenção, não se tratando de mera acomodação. A “ajuda” alegada pela Itália, portanto, não ocorreu por período razoável e houve dificuldade de acesso à justiça, em razão da natureza do confinamento.

Contudo, sobre as condições desumanas ou degradantes dos navios em Palermo e do CSPA em Lampedusa, a Corte descaracterizou a alegação do artigo 3 por parte dos solicitantes, pois como se tratava de uma emergência, de caráter humanitário, em razão da migração em massa, proveniente dos eventos da Primavera Árabe, e as instalações oferecidas eram as estruturas possíveis e disponíveis no momento, o que não absolve a República Italiana de cumprir com suas demais obrigações. 
Aqui, inicia-se uma curiosa parte da decisão: não houve violação ao artigo 3, per se, porém, houve violação do artigo 3 em conjunto ao artigo 13, porque ainda que houvesse condições degradantes, os migrantes não tiveram acesso ao meios suficientes para que denunciassem tais condições. De forma mais curiosa ainda, a Corte também não vislumbrou violação do artigo 13 quando analisado em conjunto com o artigo 4 do Protocolo 4 à Convenção, sobre expulsão coletiva de migrantes, porque o fato de não haver remédio posterior ao questionamento das recusas de ingresso no Juízo de Paz de Agrigento não significava que eles seriam submetidos a tratamento degradante caso retornados à Tunísia, o que também não fora alegado por nenhum dos solicitantes, quando ingressaram no Juízo de Paz.

O Juiz Georgios Sergides dissentiu quanto a essa última argumentação, pois o "retorno em massa" é presumível, até que se possa provar que houve análise particularizada e entrevistas a cada um dos migrantes, individualmente, o que não foi provado pelo governo italiano, afirmando também, no parágrafo 35 (EUROPEAN COURT OF HUMAN RIGHTS, 2015), e que tal violação seria imaginável.

A seguinte decisão também foi um grande exemplo de aplicação do princípio do devido processo legal a um procedimento administrativo, como é o caso da aceitação ou negativa de ingresso, embora ainda possa ser debatido sobre se de fato houve avanço no que diz respeito à proteção de migrantes, graças a decisão, ou se fora apenas uma manobra, de forma a ampliar a área cinza de atuação dos Estados, quando de seus procedimentos de expulsão.

\section{Considerações Finais}

O caso Khlaifia e outros vs. Itália evidencia falhas nos protocolos de acolhimento a migrantes, sobretudo em situações de deslocamento forçado, no que diz respeito à proteção de direitos fundamentais, como a garantia de que ninguém será exposto a tratamento desumano ou degradante, em razão de 
princípios de direito internacional dispostos nos principais documentos aceitos internacional e regionalmente pelos Estados, como é o caso dos membros da União Europeia, sobretudo aqueles que compõem o espaço Schengen.

A maneira como a Europa lida com seus migrantes - e, novamente, fazse necessário parafrasear Marie-Laure Basilien-Gainche, sobre um continente que age como se estivesse sitiado por imigrantes -, sob um viés estritamente securitário, deixando claro que há distinção entre indivíduos, hierarquizados através da categorização de vistos, nos confronta com a dinâmica de direitos de uma Europa que, desde o período de Francisco de Vitória, impõe ao "novo mundo" uma retórica de hospitalidade que não prospera dentro dos limites dos seus próprios territórios - limites crescentemente mais relativizados, em prol do não-acolhimento, através da edificação de muros e fortes esquemas de controle fronteiriço.

Apesar de não reconhecer de forma direta as graves violações ocorridas no centro de Lampedusa e nos navios em Palermo, e embora a decisão verse muito mais sobre matéria de Estado do que matéria de proteção, per se, em razão da proporção emergencial que levou os migrantes à detenção, a decisão do caso Khlaifia e outros vs. Itália abre espaço para uma discussão mais ampla sobre a crise humanitária de migração que tem as águas azuis do Mediterrâneo como principal cenário, sem que seja dada aos migrantes a garantia de que, quando tiverem seus direitos violados, poderão ser ouvidos.

A existência de estruturas altamente tecnológicas de controle de fronteira, ao realizar uma análise sobre a juridicidade das push back operations, que interceptam migrantes ainda no mar, nos traz à ideia de responsabilização de Estado sobre eventuais danos irreversíveis provocados nas vítimas, os migrantes, cujo direito ao devido processo na devolução quando essa for legalmente permitida, não se configurando hipótese de nonrefoulement - e ao direito a solicitar asilo têm de ser garantidos, sobretudo em contextos de fuga de conflitos. E que confinar migrantes em ambientes nos 


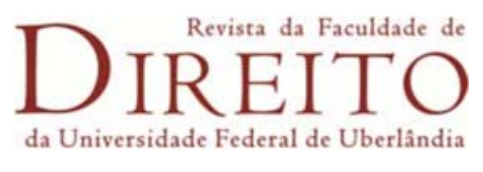

quais o mínimo necessário à preservação de sua dignidade não seja provido não pode ser considerado "ajuda", a despeito do caráter emergencial do acolhimento.

A relativização de fronteiras e os protocolos de securitização se confrontam com a sobrevivência humana, mais uma vez na história da humanidade - situação sem previsão de solução próxima, mas que lançam luz sobre a necessidade de proteção dos direitos humanos, em qualquer contexto, para que um dia a Europa possa aliar migração, integração e desenvolvimento em um novo, moderno e compatível com os ideais do século XXI, conceito de fortaleza.

\section{Referências}

BACIS, Davide. Khlaifia e altri c. Italia: l'accoglimento dei migranti al vaglio della Corte di Strasburgo. DPCE Online, v. 30, n. 2, 2017.

BADIE, Bertrand. Le migrant est l'avenir du monde. Disponível em: $<$ https://theconversation.com/le-migrant-est-lavenir-du-monde-104798> Acesso em 15 nov. 2019.

BASILIEN-GAINCHE, Marie-Laure. L'Union et les réfugiés. Une Europe sans qualités?. Revue de l'Union Européenne, n. 613, p. 598-601, 2017.

Les frontières européennes-Quand le migrant incarne la limite. Revue du marche commun et de l'Union Européenne, n. 609, p. 335-341, 2017.

BERKES, Antal. La crise migratoire de 2015-2016 et la rigidification des frontières en Europe. Matières à penser les humanités: L'indétermination des frontières disciplinaires et des catégories, v. 25, p. 89, 2018.

CÂMARA DOS DEPUTADOS. Estatuto da Corte Internacional de Justiça. Comissão de Direitos Humanos e Minorias. Disponível em: < https://www2.camara.leg.br/atividadelegislativa/comissoes/comissoes-permanentes/cdhm/comite-brasileiro-de-direitos-humanose-politica-externa/EstCortIntJust.html> Acesso em: 22 nov. 2019.

CHOATE, Mark I. "The Tunisia Paradox: Italy's Strategic Aims, French Imperial Rule, and Migration in the Mediterranean Basin." California Italian Studies 1,"Italy in the Mediterranean"(2010): 1-20. 2010.

Tunisia, Contested: Italian Nationalism, French Imperial Rule, and Migration in the Mediterranean Basin. California Italian Studies, v. 1, n. 1, 2010.

EUROPEAN COURT OF HUMAN RIGHTS. Khlaifia and Others v. Italy (GC), no. 16483/12, 1 September 2015.

EUROPEAN UNION PUBLICATIONS OFFICE. EUR-Lex - Convention determining the State responsible for examining applications for asylum lodged in one of the Member States of the European Communities - Dublin Convention. Disponível em: < https://eur-lex.europa.eu/legal-

content/EN/ALL/;jsessionid=TTrpTsvTr1VHTFy9MgfSBLjMcpPCKDrm1cPFy6J4JhpSnhcx vrD2!-228044560?uri=CELEX:41997A0819(01)> Acesso em: 28 nov. 2019. 


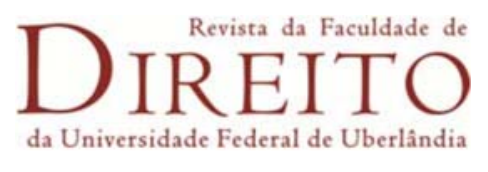

GIGLIOLI, Ilaria. Producing Sicily as Europe: Migration, colonialism and the making of the Mediterranean border between Italy and Tunisia. Geopolitics, v. 22, n. 2, p. 407-428, 2017.

GIUFFRÉ, Mariagiulia. State Responsibility Beyond Borders: What Legal Basis for Italy's Push-backs to Libya? International Journal of Refugee Law, v. 24, n. 4, p. 692-734, 2012.

Watered-down Rights on the High Seas: Hirsi Jamaa and Others V Italy (2012). International \& Comparative Law Quarterly, v. 61, n. 3, p. 728-750, 2012.

GOLDENZIEL, Jill I. Khlaifia and Others v. Italy. American Journal of International Law, v. 112, n. 2, p. 274-280, 2018.

HAYES, Ben; VERMEULEN, Mathias. The EU's New Border Surveillance Initiatives. Berlin: Heinrich Böll Foundation, 2012.

LOTH, Gaston. Le peuplement italien en Tunisie et en Algérie. Paris: Colin, 1905. pp. 219-220.

MANCINI, Pasquale S., "A nacionalidade como fundamento do direito das gentes" - (1851) in Direito Internacional - coletânea, Ed. Unijui, 2003, pp. 35-86.

ORGANIZAÇÃO DAS NAÇÕES UNIDAS. Convention de 1951 relative au statut des réfugiés. Genebra: Nações Unidas, Recueil des Traités, vol. 189, no. 2545, p. 137.

WORLD ATLAS. Mapa por Sen Nag, Oishimaya. The Biggest Islands in Italy. Disponível em: <https://www.worldatlas.com/articles/the-10-biggest-islands-of-italy.html> Acesso em: 23 nov. 2019.

Artigo recebido em: 28/11/2019.

Aceito para publicação em: 30/04/2020. 